\title{
Metastatic endophthalmitis: a rare complication of meningococcal meningitis
}

\author{
S. HAIDER \\ M.B., B.S., M.R.C.P. (Edin \& Glas), D.C.H. \\ Infectious Diseases Department, Royal Free Hospital, Coppetts Wood Hospital, \\ London N10 1JN
}

\begin{abstract}
Summary
A bacteriologically proved case of meningococcal meningitis developed metastatic endophthalmitis, a rare complication of this disease and responded satisfactorily to antibiotic therapy with complete recovery.
\end{abstract}

Meningococcal meningitis remains the most common form of bacterial pyogenic meningitis. A recent epidemiological survey in the British Medical Journal (1971) shows an increase in the annual notification of meningococcal meningitis, with 554 cases reported in 1970.

\section{Case report}

An 18-year-old girl previously healthy was admitted on 25 March 1971 with 2 days' history of headache, sore throat, pyrexia and vomiting. On examination she was conscious, coherent, had a temperature of $103^{\circ} \mathrm{F}$, bilateral conjunctival redness, more marked in the right eye, photophobia, marked neck stiffness and a positive Kernig's sign. Throat was mildly congested. Cardiovascular system, chest and abdomen were normal. Blood pressure was $120 / 80$. Neurological examination did not reveal any deficit.

Investigations. CSF turbid, WCC $1000 / \mathrm{mm}^{3}$ with predominantly polymorphonuclear leucocytes, protein $300 \mathrm{mg} / 100 \mathrm{ml}$ and sugar $30 \mathrm{~g} / 100 \mathrm{ml}$. Gram stain showed Gram-negative diplococci both extra and intracellular, culture yielded $N$. meningitidis. Two blood cultures also grew $N$. meningitidis. Organisms were identified belonging to group $\mathrm{C}$ and were senstive to penicillin and sulphonamides. Nose, throat and conjunctival swabs yielded no growth of $N$. meningitidis. Hb $11.9 \mathrm{~g} / 100 \mathrm{ml}$, WCC $12000 / \mathrm{mm}^{3}, 87 \%$ polymorphonuclear leucocytes. Blood urea, electrolytes, X-ray chest and electrocardiogram were within normal limits.

Treatment and progress. The patient was given 30 mega units of penicillin $G$ in half strength Hartman's solution intravenously/24 hr. On $26 \mathrm{March}$ she developed pain and loss of vision in her right eye. She was seen by the consultant ophthalmologist who noted signs of severe uveitis with considerable exudation into the anterior chamber and diagnosed metastatic endophthalmitis.

Her therapy was changed to 20 mega units of penicillin $G$ and sodium sulphadimidine $8 \mathrm{~g}$ intravenously $/ 24 \mathrm{hr}$ with local instillation of gutt. penicillin BPC and gutt. atropine $1 \%$ every $4 \mathrm{hr}$. Vision in the right eye and signs of meningitis improved gradually. This therapy was continued for 14 days. On 30 March she developed herpes labialis which responded satisfactorily to local application of $5 \%$ idoxuridine in dimethyl sulphoxide solution. At the time of discharge on 22 April her vision in the right eye was $6 / 6$ with some degree of residual posterior uveitis and she had no neurological deficit.

\section{Comment}

Ocular complications in meningococcal infection are rare. Irido-choroiditis was noted in seven out of 706 patients $(1 \%)$ by Banks 1951 . Beeson \& Westerman (1943) recorded eye involvement in $0.5 \%$ of their cases.

The case presented here is of interest in that the meningitis was associated with conjunctival chemosis due to uveitis and exudation in the anterior chamber and not a meningococcal conjunctivitis. Local antibiotic therapy is preferred in such cases as penicillins in therapeutic levels do not penetrate the intact blood-aqueous-humour barrier in adequate amounts to combat severe intra-ocular infection. Free plasma penicillin levels have to be above $21 \mu \mathrm{g} / \mathrm{ml}$ before any intraocular penetration takes place.

\section{Acknowledgments}

I am grateful to Dr Hillas Smith for his permission and directions in writing this case and $\mathrm{Mr} \mathrm{H}$. E. Hobbs, Consultant Ophthalmologist, Royal Free Group Hospitals, for diagnosis and advice in ocular management of the patient.

\section{References}

British Medical Journal (1971) Epidemiology, bacterial meningitis, based on the report by the Public Health Laboratory Service, U.K. British Medical Journal, 2, 230.

BANks, H.S. (1951) Modern Practice in Infectious Fevers, Vol. I, p. 323. Butterworth, London.

Beeson, P. \& Westerman, E. (1943) Cerebro-spinal fever. Analysis of 3575 case reports, with special reference to sulphonamide therapy. British Medical Journal, 1, 497. 